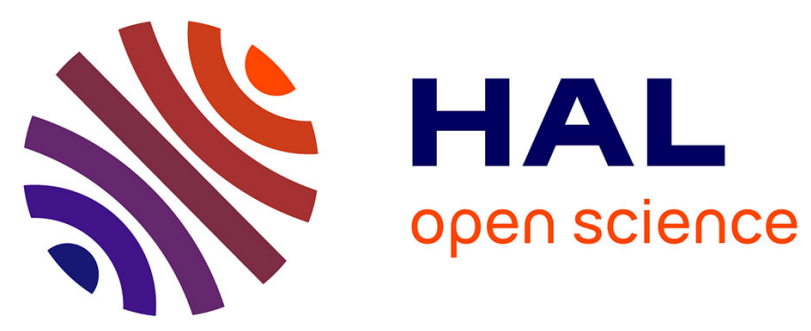

\title{
Prediction of treatment response and the effect of independent component neurofeedback in obsessive-compulsive disorder: a randomized, sham-controlled, and double-blind study
}

Jana Kopřivová, Marco Congedo, Michal Razska, Ján Praško, Martin

Brunovský, Jiří Horáček

\section{To cite this version:}

Jana Kopřivová, Marco Congedo, Michal Razska, Ján Praško, Martin Brunovský, et al.. Prediction of treatment response and the effect of independent component neurofeedback in obsessive-compulsive disorder: a randomized, sham-controlled, and double-blind study. Neuropsychobiology, 2013, 67 (4), pp.210-223. 10.1159/000347087 . hal-00908604

\section{HAL Id: hal-00908604 https://hal.science/hal-00908604}

Submitted on 25 Nov 2013

HAL is a multi-disciplinary open access archive for the deposit and dissemination of scientific research documents, whether they are published or not. The documents may come from teaching and research institutions in France or abroad, or from public or private research centers.
L'archive ouverte pluridisciplinaire HAL, est destinée au dépôt et à la diffusion de documents scientifiques de niveau recherche, publiés ou non, émanant des établissements d'enseignement et de recherche français ou étrangers, des laboratoires publics ou privés. 
Title: Prediction of treatment response and the effect of independent component neurofeedback in obsessive-compulsive disorder: a randomized, sham-controlled, and double-blind study

Authors: Jana Kopřivová a, b, Marco Congedo ${ }^{c}$, Michal Raszka ${ }^{\text {a, b }}$, Ján Praško ${ }^{a, d}$, Martin Brunovský ${ }^{\text {a, b }}$, Jiří Horáček $^{a, b}$

a Prague Psychiatric Center, Ústavní 91, Prague 8, Czech Republic

${ }^{b}$ Third Faculty of Medicine, Charles University, Ruská 87, Prague 10, Czech Republic

${ }^{c}$ Team ViBS (Vision and Brain Signal Processing), CNRS (Centre National de la recherche Scientifique), GIPSA-lab, 961 rue de la Houille Blanche, Domaine universitaire, BP 46, Grenoble, France

${ }^{d}$ Department of Psychiatry, University Hospital Olomouc, I.P. Pavlova 6, Olomouc, Czech Republic

Corresponding author: Jana Kopřivová, Prague Psychiatric Center, Ústavní 91, 18103 Prague 8, Czech Republic Tel. +420266003 361, Fax: +420266003366

E-mail address: koprivova@pcp.If3.cuni.cz 
Key-words: Obsessive-Compulsive Disorder; Neurofeedback; Independent Component Analysis; Treatment Response

\section{Abstract}

AIMS: The goal of this study was to assess the effect of independent component neurofeedback (NFB) on EEG and clinical symptoms in patients with obsessive-compulsive disorder (OCD). Subsequently we explored predictors of treatment response and EEG correlates of clinical symptoms.

METHODS: In a randomized, double blind and parallel design 20 in-patients with OCD underwent 25 sessions of NFB or sham feedback (SFB). NFB aimed at reducing EEG activity in an independent component previously reported abnormal in this diagnosis. Resting state EEG recorded before and after the treatment was analysed to assess its post-treatment changes, relationships with clinical symptoms and treatment response.

RESULTS: Overall, clinical improvement in OCD patients was not accompanied by EEG change as assessed by standardized low-resolution electromagnetic tomography and normative independent component analysis. Pre- to post-treatment comparison of the trained component and frequency did not yield significant results, however, in the NFB group, the nominal values at the down-trained frequency were lower after treatment. The NFB group showed significantly higher percentage reduction of compulsions compared to the SFB group $(p=0.015)$. Pre-treatment higher amount of delta $(1-6$ $\mathrm{Hz}$ ) and low alpha oscillations as well as lower amount of high beta activity predicted a worse treatment outcome. Source localization of these delta and high beta oscillations corresponded with previous EEG resting state findings in OCD patients compared to healthy controls.

\section{CONCLUSION:}

Independent component NFB in OCD proved useful in percentage improvement of compulsions. Based on our correlation analyses we hypothesize that we targeted a network related to treatment resistance. 


\section{INTRODUCTION}

Obsessive-compulsive disorder (OCD) is a common neuropsychiatric disorder which symptoms (recurrent intrusive thoughts and repetitive behaviours) are often severe or even disabling and thus addressing not only medical but also social and economical issues. About half of OCD patients do not respond or do not respond sufficiently to serotonine reuptake inhibitors and only one third of treatment non-responders show meaningful improvement after antipsychotic augmentation [1]. A search for new therapeutic approaches is therefore still needed. Functional and morphological studies consistently show the importance of fronto-striatal circuits in OCD pathophysiology [2] and provide a substantial body of evidence for neurobiological basis of OCD. Therefore learning aimed at specific neurobiological characteristics, such as the activity of orbitofrontal or anterior cingulate cortex, might contribute to the treatment of this disorder. This form of learning can be achieved via electroencephalographic biofeedback (or neurofeedback, NFB) known since the end of the 1960s $[3,4]$. The brain electrical activity can be detected and fed back with a minimal delay in the form of a sensorial (visual or auditory) object, dynamically varying according to the instantaneous brain activity. Thus, an individual can achieve a certain degree of awareness or even control over his brain activity generating the measured signal. In such a way, it is possible to normalize the pathologic brain activity [5]. Over the years of its clinical application, neurofeedback proved effective in the treatment of attention disorders [6] and epilepsy [7]. In the case of other disorders, incl. anxiety disorders [8], some success has also been reported but the data are still insufficient and research is in progress. The application of NFB in the treatment of OCD has not been systematically investigated, however, encouraging case-studies have been described [9].

Traditionally, NFB method is based on the signal of one or two scalp electrodes and the feedback has low spatial specificity. Moreover, the orbitofrontal and anterior cingulate cortices are hard to access because their contribution to the scalp signal is low. These shortcomings can be tackled by multichannel neurofeedback based on new methods of EEG analysis $[10,11]$. As a promising approach it appears the derivation of feedback signal by means of blind source separation methods, BSS [12], for example by independent component analysis, ICA. Using BSS, it is possible to decompose the recorded signal from the scalp into independent signals (components) pointing to intracranial generators of the registered activity. It is assumed that these components represent the activity of simple and spatially delimited neuronal populations which is separated from other brain activity, biological artefacts and noise. Thus, they become promising candidates for the feedback signal used in the learning process to regulate the selected activity in the desired direction. This form 
of neurofeedback has not been tested so far and thus provides an opportunity to improve current treatment methods. Independent component neurofeedback is based on individual diagnosis of pathological EEG sources and the intervention can be adjusted to the needs of each patient.

In our study, the independent component neurofeedback is based on the group independent component EEG analysis of normal subjects that revealed seven independent sources replicated in two normative databases [13]. The component of interest for this study is component number 1 as described in [13] because it has been reported to differentiate between OCD patients and healthy controls [14]. This component has the highest power in anterior cingulate (especially in BA 24 and 25), insula, middle and superior fontal gyrus, paracentral lobule, parahippocampal and subcallosal gyrus. The localization and frequency spectrum of the component 1 are reported in the study by Congedo et al. [13].

It has been suggested that this component relates to the salience of internal and external stimuli and could be considered an attentional network focusing on salient information [13]. Such an assumption is congruent with the typical overfocus of $O C D$ patients at their symptoms and symptom-related information from the external world. A previous study [14] reported that OCD patients had higher low-frequency activity $(3-6 \mathrm{~Hz})$ in this component. With respect to the overactive performance monitoring system in $O C D$ as reflected by an enhanced error-related negativity [15] arising from frontal midline theta [16], the finding of an enhanced theta activity in the midline component implicated in attentional processes is not surprising in OCD.

The aim of our study was to assess if the downtraining of the abnormally high activity of the reported independent component at an individually adjusted frequency would influence EEG parameters and clinical symptoms in patients with OCD. We hypothesized that (1) the independent component EEG neurofeedback will lead to a change of the activity of the trained component in the direction of training, i.e. the abnormal brain activity (power in the selected frequency band) will tend to normalize, and (2) that the independent component EEG neurofeedback will improve clinical symptoms of obsessive-compulsive patients. In the subsequent analyses, we explored EEG predictors of treatment response and correlates of clinical symptoms.

\section{MATERIALS AND METHODS}

\section{Subjects and design}


The a priori performed power analysis yielded 20 subjects (10 per each group) as a sufficient sample size to detect a large effect size $(w>0.5)$ for a given power of $80 \%$ and alpha of $5 \%$. Therefore, twenty in-patients diagnosed with OCD according to ICD-10 [17] and DSM-IV [18] criteria aged between 19 and 42 years were included in the study. Two patients dropped out for motivation or family reasons after completing two and three sessions, respectively. Because OCD is known as an heterogeneous disorder, as an inclusion criterion, all patients had to show abnormal EEG power in the first EEG source derived through a group independent component analysis [13] as described above. Nine patients (31\%) meeting all the other criteria did not fulfil this requirement and therefore were not included in the study (Fig. 1).

Only patients who were either drug-free $(n=5)$ or medicated with SSRIs $(n=15)$ were enrolled in the study. Twenty six patients $(47 \%)$ of the total number of screened patients $(n=55)$ were using other or additional medication (such as antipsychotic drugs, benzodiazepines, and clomipramine). These patients were not included in the study because there are no studies of the effect of these drugs on the power spectrum of the first component. The medication was stable four weeks before the study and remained unchanged until its end. Exclusion criteria involved concurrent severe or chronic medical disease, substance abuse, mental retardation, organic mental disorder, lifetime history of psychosis, mood disorders, severe head injury and neurosurgery. The demographic and clinical characteristics are shown in Table 2.

All patients were hospitalized and participated in a six-week standard treatment programme including cognitive-behavioural therapy and completed 25 thirty-minute ( $3 \times 10$ minutes) sessions of neurofeedback (10 patients, two dropped out) or sham feedback (10 patients) scheduled on every working day. Randomization was performed before the beginning of the study for 20 subjects planned to be enrolled in the study and the information about the training condition was stored in the NFB training software. The criterion for randomization was an equal number of subjects in the groups. The patient, the trainer as well as the rater were blind to the training condition. At the beginning and at the end of the treatment all patients underwent a resting state EEG examination and were interviewed by a trained psychiatrist to assess the severity of their clinical symptoms. Symptom severity was measured using the Yale-Brown Obsessive Compulsive Scale - YBOCS [19], self-rated Beck Anxiety Inventory [20] and Beck Depression Inventory [21]. The study was carried out in accordance with the Declaration of Helsinki and written informed consent was obtained from all subjects. The study was approved by the local ethical committee. 


\section{EEG recording and data preprocessing}

EEG was recorded with a BrainScope differential amplifier (Unimedis, Ltd., Czech Republic) against the AFz reference with a sampling rate of $250 \mathrm{~Hz}$ from 19 scalp locations according to the international 10-20 system using the ECl electro-cap (Electro-Cap International, Inc., Eaton, USA). The impedances were kept below 5 k $\Omega$. Neurofeedback or sham feedback task-related EEG was recorded with eyes open during each training session. Resting state EEG was recorded at the beginning and at the end of the study during eyes-closed (5 minutes) and eyes-open ( 5 minutes) conditions. During the recording alertness was monitored and if patterns of drowsiness appeared in the EEG, the subjects were aroused by acoustic stimuli. The study was performed in the frame of a standardized daily routine in mental hospital ensuring approximately the same amount of sleep and activity in all patients.

Data were analyzed using the NTE Pack 2005 freeware including Eureka EEG tool and MHyT statistical software (Nova Tech EEG, Inc., Mesa, Arizona, USA). First, the data were imported into Eureka software to remove episodic artifacts. If necessary, continuous muscle artifacts or frequent eye-blinks were then removed as independent components in ICoN software (http://sites.google.com/site/marcocongedo/software/nica). At least $60 \mathrm{sec}$ of artefact-free data were kept for further analysis. Artifact-free data were controlled for wakefulness and if segments with signs of drowsiness were present, they were removed before analysis. All data were filtered between $1-32 \mathrm{~Hz}$, they were re-referenced against the average reference and downsampled to $128 \mathrm{~Hz}$.

\section{Neurofeedback and sham feedback}

Neurofeedback was based on the group ICA performed on the data in the Nova Tech EEG database including 84 healthy subjects [13]. To recover sources in each individual patient, the data of each subject was first premultiplied by the seven-component reduced demixing matrix used in the normative ICA analysis [13] and then passed through an additional ICA, also performed by ICON software. This procedure ensures that the trained component individually corresponds to a dipolar source. Among the components found in the second ICA pass, the one that correlated most (a Pearson correlation of at least 0.65 computed on at least 7680 time points) with the component 1 derived from the database, was taken for the training and downtrained at a frequency based on individual deviations from the normative sample. For example, in the case shown in the 
Fig. 2 we downtrained the individual component filtered in the band-pass range of $4-6 \mathrm{~Hz}$. Three patients had abnormal activity in the low beta band (2 NFB, 1 SFB) and 17 at low frequencies. The decision to train either low or low beta frequencies was supported by the research by Onton et al. [22] who showed that bursts of low beta $(<20 \mathrm{~Hz})$ activity may be an integral feature of frontal task-related brain dynamics associated with frontal midline theta. Moreover, an increased coupling between slow (delta and theta) and fast (beta) frequency oscillations has been demonstrated in anxiety [23]. The training parameters for all subjects are shown in Table 1.

For the training we used custom-made software with a feedback screen designed according to [10] and consisting of a line and squares moving up and down according to the selected EEG parameters. The patients also received an auditory signal of reward that disappeared if the selected EEG activity was above the set threshold. In the neurofeedback group, the feedback screen reflected the true real-time EEG activity, i.e., the power of the selected component in the selected frequency. In the sham feedback group, the feedback screen was guided by EEG signal previously recorded during neurofeedback training of another patient. This approach ensured maximal similarity of the two conditions and enabled to eliminate the placebo effect and to analyze the effect of the true neurofeedback intervention. All patients were explained the feedback principle and were instructed to keep the squares below threshold. The threshold was set automatically after the first two sessions so as the training success was around $25 \%$ and then it remained stable to allow the patients to follow their progress. During the training, the EEG signal was hidden to keep the trainer unaware of the patient's condition. The quality the EEG signal could be checked before the training as well as between the three trials of one session.

\section{Statistical analyses of demographic and clinical data}

The demographic and clinical data were described by non-parametric descriptive statistics (Table 2). The MannWhitney U-test was used to compare the NFB and SFB group, the Wilcoxon signed-rank test was applied to explore pre- and post-treatment data and the chi-square test was used to test categorial variables. The results below the alpha level of 0.05 were considered significant.

\section{Pre- and post-treatment EEG analysis}


EEG recorded before and after treatment was analysed using group ICA analysis and standardized lowresolution electromagnetic tomography - sLORETA [24]. For sLORETA, we defined seven frequency bands between $1-32 \mathrm{~Hz}$ (delta: $1-6 \mathrm{~Hz}$, theta: $6.5-8 \mathrm{~Hz}$, alpha1: $8.5-10 \mathrm{~Hz}$, alpha2: $10.5-12 \mathrm{~Hz}$, beta1: $12.5-18$ $\mathrm{Hz}$, beta2: $18.5-21 \mathrm{~Hz}$, beta3: $21.5-32 \mathrm{~Hz}$ ) and computed absolute and relative power in 2394 cortical voxels. The data were log transformed, smoothed with $14 \mathrm{~mm}$ moving average and the groups (pre-treatment vs. posttreatment and NFB vs. SFB) were compared by means of randomization-permutation $t$-max statistics in MHyT software. All analyses were performed by the use of the repeated-measures two-sided $t$-max-statistics test guaranteeing that the family-wise type I error rate (FWER) across the 2394 voxels did not exceed the nominal level $0.05[25]$.

Furthermore, the absolute and relative power values in each voxel were correlated with the symptom severity (Y-BOCS, BAI and BDI score), treatment outcome and treatment response using Pearson correlation coefficient of log transformed data and randomization-permutation statistics to correct for multiple comparison. The analysis was performed in MHyT software. We correlated (1) pre-treatment EEG with the severity of clinical symptoms before treatment, (2) pre-treatment EEG with the severity of clinical symptoms after treatment (search for predictors of the worse treatment outcome) and (3) pre-treatment EEG with percentage change of clinical symptoms (search for predictors of the treatment response magnitude).

Group ICA was performed based on the data in the database [13]. Before and after the treatment, all groups were compared to the normative database to detect if the component power normalized. Moreover, for each patient, we extracted the power of the component between $1-32 \mathrm{~Hz}$ with $2 \mathrm{~Hz}$ resolution and compared the pre- and post-treatment values by randomization-permutation statistics in MHyT software. We also analyzed the data (the log-transformed averaged absolute and relative power of the individual frequency band selected for the training) using a two-way ANOVA with time (pre/post) as a within-subjects factor and condition (active/sham) as a between-subjects factor. Furthermore, we computed correlations of the component power with symptom severity, treatment outcome and treatment response as described above.

Additionally, we re-ran all the analyses for the low-frequency subgroup only, i.e. for the 15 patients whose component 1 showed abnormally high power at low frequencies before treatment.

\section{RESULTS}




\section{Demographic and clinical data}

Demographic and clinical data are shown in Table 2. Both groups (NFB and SFB) were equivalent in all demographic as well as clinical characteristics. After treatment, the NFB group showed a greater percentage reduction in compulsion score compared to SFB $(p=0.015)$. This result was no longer significant in the lowfrequency subgroup. The absolute scores of subjectively reported anxiety and depression as measured with BAI and $\mathrm{BDI}$ reduced after treatment only in the SFB group. In the low-frequency subgroup only the BAI score improved in the SFB group $(p=0.047$ ). However, the most specific OCD symptoms (obsessions and compulsions) improved after NFB and SFB equally in both, the whole group as well as in the low-frequency subgroup $(p<0.05)$.

\section{Pre- and post-treatment EEG analysis}

sLORETA analysis did not reveal any significant change after treatment in NFB, SFB or in the whole group ( $p<$ 0.05). However, a separate pre- to post-treatment SLORETA comparison of the low-frequency subgroup showed a post-treatment relative power decrease in the alpha1 frequency band localized in posterior cingulate gyrus (BA 31, Talairach coordinates [26]: $x=11, y=-25, z=43$ ) after NFB but not SFB (see Table 3). In the component of interest, before treatment both groups showed higher relative power values (above the 95 . percentile of the normative database) at low frequencies $(5-8 \mathrm{~Hz})$ and the NFB group had also higher power in the relative beta1 band $(13-14 \mathrm{~Hz})$ as compared to the normative database (see Fig. 3 ). Pre-treatment lowbeta excess was not present in the low-frequency subgroup. Post-treatment, the relative beta band and a part of the theta band in the NFB group fell below the 95. percentile of the normative database. In the SFB group, relative theta power values remained above the 95. percentile. The whole NFB subgroup showed lower relative beta3 $(25-26 \mathrm{~Hz})$ power in the trained component after treatment (Table 3). However, the result of ANOVA with a within factor pre-post and between factor active-sham was not significant at this frequency $(F=0.04, p=$ 0.853). Statistical comparisons of pre-treatment and post-treatment component performed by a paired $t$-test showed a trend towards a decrease within the individually defined frequency band selected for the training only in the NFB group ( $p=0.147$, one-sided). No such trend was observed in the SFB group ( $p=0.817$, onesided). The results of ANOVA with a within factor pre-post and between factor active-sham were not significant for the whole group $(F=1.00, p=0.331$, see Table 3, Fig. 4) or for the low-frequency subgroup $(F=1.73, p=$ $0.212)$. 


\section{Correlation analyses}

\section{sLORETA correlations}

Pre-treatment EEG sLORETA correlations with the severity of clinical symptoms before treatment did not yield significant results in the whole group or in the low-frequency subgroup. However, in the low-frequency subgroup, pre-treatment EEG sLORETA correlations with the severity of clinical symptoms after treatment showed a positive correlation between absolute delta power in the medial frontal cortex (esp. ACC, also extending to several voxels in the right parahippocampal gyrus) and Y-BOCS score $(r \geq 0.660, p<0.05$, Fig. 5). Moreover, in the low-frequency subgroup, pre-treatment absolute beta2 activity $(18.5-21 \mathrm{~Hz})$ in the bilateral medial orbitofrontal cortex (more on the left side), left pregenual anterior cingulate, lateral orbitofrontal, medial frontal and dorsolateral prefrontal cortex was positively related to the severity of obsessive-compulsive symptoms post-treatment ( $r \geq 0.695, p<0.05$, Fig. 6).

Percentage change of the Y-BOCS score correlated with pre-treatment alpha1 and beta3 power in the whole group as well as in the low-frequency subgroup (Table 4). In the whole group, negative correlation between relative alpha1 power and percentage change of the Y-BOCS score was found in the left middle and superior temporal gyrus (BA 22, 29, 41, 29), postcentral gyrus (BA 40) and insula (BA 13) $(r \leq-0.635, p<0.05$, Fig. 7). In the low-frequency subgroup, percentage change of the Y-BOCS score was negatively related also to the amount of absolute alpha1 power in the left fusiform and parahippocampal gyrus before treatment $(r \leq-0.738, p<$ 0.01). Similarly, absolute alpha1 power in a more widespread region including left fusiform, bilateral parahippocampal gyrus and uncus, left inferior, middle and superior temporal gyrus, left insula $(r \geq 0.766, p<$ 0.01) as well as (at lower significance level $p<0.05$ ) subgenual ACC and medial frontal cortices (BA 25), right parietal $(B A 7,40)$ and occipital (BA 18, 19) regions were positively related with obsessive-compulsive symptom severity post-treatment in the low-frequency subgroup. Maximal correlation values were found in the left fusiform and left inferior temporal gyrus. Positive correlation between relative beta3 power and percentage change of the Y-BOCS score was found in the bilateral medial, middle and superior frontal gyrus (BA 6), cingulate gyrus (BA 23, 24, 31) precentral gyrus (BA 4, 6), postcentral gyrus (BA 1, 2, 3, 5), paracentral lobule (BA 5, 31), precuneus (BA 7) and the right insula (BA 13), inferior parietal lobule (BA 40), superior (BA 29) and middle temporal gyrus (BA 21, 22) in the whole group ( $r \geq 0.653, p<0.05$, Fig. 8). In addition, in the low- 
frequency subgroup, significant voxels were found also in the subgenual and dorsal anterior cingulate, bilateral insula, and in the right parahippocampal, superior temporal and fusiform gyrus $(r \geq 0.706, p<0.05)$.

\section{The trained component}

Percentage change of the total Y-BOCS score correlated positively with pre-treatment relative component power at $25-30 \mathrm{~Hz}(r \geq 0.625, \mathrm{p}<0.05)$. A similar result (at $23-30 \mathrm{~Hz}$ ) was obtained for the low-frequency subgroup. In addition, in the low-frequency subgroup, the results indicated a trend towards a positive relationship between low-frequency absolute component power $(5-6 \mathrm{~Hz})$ before treatment and the severity of obsessions post-treatment $(r \geq 0.656, p<0.07$, Table 4). This result would be significant in a one-sided test that could actually be applied given the previous finding of increased low-frequency power in this component in OCD compared to healthy controls [14]. Correlation analysis of the pre-treatment component power with clinical symptoms before treatment did not reveal significant results or trends.

\section{DISCUSSION}

Although there were no significant pre- to post-training differences in the trained power of the trained component, in the NFB group the component power at most trained frequencies fell below the 95th percentile of the normative database after the training. This was consistent with the hypothesized normalization effect of the NFB on EEG. The percentage improvement of the compulsion score was significantly greater in the NFB group compared to patients receiving SFB. The other clinical outcome measures did not differ between the NFB and SFB groups, as well as there were no differences in EEG parameters as measured by sLORETA and normative ICA with the exception of a post-treatment relative power decrease in the alpha1 frequency band in the posterior cingulate gyrus and a decrease of absolute beta3 power in the trained component after NFB.

There are several reasons to explain these mostly negative findings. First, it is possible that EEG change after NFB is small and could be detected only on a larger sample. In favour of such a hypothesis is the study by Gevensleben et al. [27] that found a slight pre to post theta reduction in the NFB group in a much larger sample. Second, the number of sessions in this study was adopted with respect to the length of the patient hospitalization at the clinic ( 6 weeks). However, it is possible that more NFB training sessions would be needed to prove the eventual effect of NFB on EEG of OCD patients. Third, according to Lansbergen et al. [28] who failed to prove superiority of NFB over placebo NFB in ADHD, an implementation of active learning strategies 
[e.g. 27] may be an important factor for NFB efficacy. The same authors also hypothesize that manually adjusted reward thresholds may work better than the automatic ones.

As no EEG change in the whole sample was found in a pre-post testing despite significant clinical improvement of both groups, it is possible that other methods of quantitative EEG analysis would be more successful in detecting EEG changes than sLORETA and NICA. It is also possible that EEG abnormalities found in OCD may represent a trait marker that does not depend on the actual clinical state and its change. Even in such a case, NFB aimed at normalizing the abnormal EEG features would still be useful by targeting a network that can be implicated in OCD pathophysiology and treatment responsiveness or non-responsiveness. Indeed, our results suggest that we targeted a network related to treatment resistance.

First, in the low-frequency subgroup we demonstrated that patients who had higher power at low frequencies $(1-6 \mathrm{~Hz})$ in the ACC before treatment showed a worse treatment outcome (higher Y-BOCS score). The frequency and spatial localization of this finding was identical with the results from EEG comparison of OCD patients and healthy controls reported in [14]. Moreover, our previous voxel-based morphometry study showed a decreased gray matter density in OCD in a similar brain region [29].

Second, in the low-frequency subgroup we found that in part similarly localized beta activity $(18.5-21 \mathrm{~Hz})$ was positively related with symptom severity post-treatment. Consistently, increased pre-treatment beta power in the rostral ACC and medial frontal gyrus has previously been linked to a worse treatment response in OCD [30]. Low-frequency oscillations and beta activity are functionally related. It has been suggested that the delta network (primarily based within the OFC and ACC) drives local beta oscillations in the same regions and coordinates the timing of neuronal activities through delta-beta coupling [23]. Our finding of the relationship between the treatment response and both, slow and fast frequencies provides further support for a functional relationship of these two frequency bands in OCD.

Third, in the low-frequency subgroup we observed post-treatment relative low alpha power reduction in the posterior cingulate after NFB. As alpha oscillations have been associated with inhibitory processes [31] and with lower EEG alpha-BOLD signal correlation [32], it could be hypothesized that the posterior cingulate activity increased after NFB. Given the link between higher pre-treatment activity in posterior cingulate and a better treatment outcome $[33 ; 34]$ this might suggest that NFB training led to a shift toward a better treatment responsiveness. However, because the EEG change outside the trained component was unexpected as well as 
due to a small number of subjects in the low-frequency NFB subgroup, these results should be replicated and further explored.

Percentage change of the Y-BOCS score was positively related to the high beta power in the selected independent component as well as in cortical voxels localized by SLORETA in the midcingulate gyrus and adjacent areas of the frontal and parietal cortex extending to the lateral surface of the hemispheres. High beta power excess in OCD compared to healthy controls in a very similar location has previously been reported by Sherlin and Congedo [35] as well as by Velikova et al. [36]. In this context, the post-treatment decrease in beta3 power in the trained component after NFB might reflect a shift from an OCD EEG pattern to a normal pattern. In our study, the most significant voxels have been found in the midcingulate containing motor cingulate area [37] and in the Brodmann area 6 encompassing supplementary motor cortex. Both of these structures are involved in performance monitoring [38] and are connected with other cortical and subcortical regions related to OCD. Moreover, the parietal cortex has also been described as a part of the dorsolateral prefronto-striatal loop implicated in OCD pathophysiology [2]. As beta is an excitatory frequency band [39], its presence suggests an activation of the relevant brain regions. Treatment response was further negatively related to the low alpha activity especially in the temporal structures and left insula. In OCD compared to healthy controls, the middle or superior temporal cortex was described as smaller [29; 40] or thinner [41] and functional abnormalities have also been reported in this area [42]. The neighbouring insula is implicated in a variety of neuropsychiatric disorders [43] including OCD [44]. In the low-frequency subgroup, the correlation between the amount of alpha power and treatment response was highest in the fusiform gyrus, a structure that (together with posterior cingulate) has been reported to be less active during anticipation in OCD. Anticipation of unwanted and disturbing events can be regarded as an epitome of obsessions, the core symptom of OCD [45].

Several limitations of the study should be acknowledged. First, the spatial specificity of EEG methods is limited and is not as accurate as direct anatomical measurements. Therefore, the anatomical labels used throughout the text should be interpreted with caution. Second, it should be noted, that the independent component neurofeedback used in our study is not the only option in OCD. For example, in the view of new findings about the high beta in OCD reported by $[35 ; 36]$ and found also in our study, it would be interesting to use LORETA NFB targeting at high beta in the midcingulate and adjacent areas. Finally, because the abnormal power spectrum in the first component was an inclusion criterion in our study, the results are limited only to this $O C D$ phenotype. 
In conclusion, our study found that (1) patients receiving NFB showed higher percentage improvement of the compulsion score compared to patients receiving SFB, (2) NFB led to a small and non-significant EEG change in the direction of training, (3) clinical improvement in OCD patients was not accompanied by EEG change as assessed by SLORETA and NICA, and (4) pre-treatment EEG was predictive for the treatment outcome. Interestingly, low-frequency EEG oscillations in the medial frontal and especially anterior cingulate cortex and the high beta oscillations localized similarly as well as more posteriorly, in the midcingulate, supplementary motor cortex and adjacent areas found in our study to predict treatment outcome, have previously been reported overactive in OCD patients compared to healthy subjects [14; 35; 36]. Further research is needed to elucidate the relationship between these two EEG patterns and their role in the treatment responsiveness in OCD.

\section{ACKNOWLEDGEMENTS}

This work was supported by the grant IGA NS $9751-3 / 2008$ and NT 11226 provided by the Ministry of Health of the Czech Republic.

\section{REFERENCES}

1 Bloch MH, Landeros-Weisenberger A, Kelmendi B, Coric V, Bracken MB, Leckman JF: A systematic review: antipsychotic augmentation with treatment refractory obsessive-compulsive disorder. Mol Psychiatry 2006;11(7):622-632.

2 Menzies L, Chamberlain SR, Laird AR, Thelen SM, Sahakian BJ, Bullmore ET: Integrating evidence from neuroimaging and neuropsychological studies of obsessive-compulsive disorder: the orbitofronto-striatal model revisited. Neurosci Biobehav Rev 2008;32(3):525-549.

3 Kamiya J: Conscious control of brain waves. Psychology Today 1968;1(11):56-60.

4 Wyrwicka W, Sterman MB: Instrumental conditioning of sensorimotor cortex EEG spindles in the waking cat. Physiology \& Behavior 1968;3(5):703-707.

5 Beauregard M, Lévesque J: Functional magnetic resonance imaging investigation of the effects of neurofeedback training on the neural bases of selective attention and response inhibition in children with attention-deficit/hyperactivity disorder. Appl Psychophysiol Biofeedback 2006;31(1):3-20.

6 Arns M, de Rider S, Strehl U, Breteler M, Coenen A: Efficacy of neurofeedback treatment in ADHD: the effects on inattention, impulsivity and hyperactivity: a meta-analysis. Clin EEG Neurosci 2009;40(3):180-189.

7 Sterman MB, Egner T: Foundation and practice of neurofeedback for the treatment of epilepsy. Appl Psychophysiol Biofeedback 2006;31(1):21-35.

8 Moore NC:. A review of EEG biofeedback treatment of anxiety disorders. Clin Electroencephalogr 2000;31(1):1-6.

9 Hammond DC: QEEG-guided neurofeedback in the treatment of obsessive compulsive disorder. J Neurother 2003;7:25-52.

10 Congedo M, Lubar JF, Joffe D: Low-resolution electromagnetic tomography neurofeedback. IEEE Trans Neural Syst Rehabil Eng 2004;12(4):387-397.

11 Cannon R, Lubar J, Congedo M, Thornton K, Towler K, Hutchens T: The effects of neurofeedback training in the cognitive division of the anterior cingulate gyrus. Int J Neurosci 2007;117(3):337-357. 
12 Jutten C, Herault J: Blind separation of sources, Part 1: an adaptive algorithm based on neuromimetic architecture. Signal Processing 1991;24(1):1-10. MARCO

13 Congedo M, John RE, De Ridder D, Prichep L: Group independent component analysis of resting state EEG in large normative samples. Int J Psychophysiol 2010;78(2):89-99.

14 Koprivova J, Congedo M, Horacek J, Prasko J, Raszka M, Brunovsky M, Kohutova B, Höschl C: EEG source analysis in obsessivecompulsive disorder. Clin Neurophysiol 2011;122(9):1735-1743.

15 Endrass T, Klawohn J, Schuster F, Kathmann N: Overactive performance monitoring in obsessive-compulsive disorder: ERP evidence from correct and erroneous reactions. Neuropsychologia 2007;46(7):1877-1887.

16 Luu P, Tucker DM, Makeig S: Frontal midline theta and the error-related negativity: neurophysiological mechanisms of action regulation. Clin Neurophysiol 2004;115(8):1821-1835.

17 World Health Organisation (WHO): ICD-10: The ICD-10 classification of mental and behavioural disorders: clinical descriptions and diagnostic guidelines. Geneva, World Health Organisation, 1992.

18 American Psychiatric Association: Diagnostic and statistical manual of mental disorders (DSM-IV), ed 4. Washington DC, American Psychiatric Association, 1994

19 Goodman WK, Price LH, Rasmussen SA, Mazure C, Fleischmann RL, Hill CL, Heninger GR, Charney DS: The Yale-Brown Obsessive Compulsive Scale. I. Development, use, and reliability. Arch Gen Psychiatry 1989;46:1006-1011.

20 Beck AT, Emery G: Anxiety disorders and phobias: A cognitive perspective. New York, Basic Books, 1985.

21 Beck AT, Ward C, Mendelson M: Beck Depression Inventory (BDI). Arch Gen Psychiatry 1961;4:561-571.

22 Onton J, Delorme A, Makeig S. Frontal midline EEG dynamics during working memory in obsessive-compulsive disorder. Neurolmage 2005;27:341-356.

23 Knyazev GG: Cross-frequency coupling of brain oscillations: an impact of state anxiety. Int J Psychophysiol 2011;80(3):236-45.

24 Pascual-Marqui RD: Standardized low-resolution brain electromagnetic tomography (sLORETA): technical details. Methods Find Exp Clin Pharmacol 2002;24 Suppl:5-12.

25 Westfall PH, Young SS: Resampling-Based Multiple Testing: Examples and Methods for p-Value Adjustment. New York, WileyInterscience, 1993.

26 Talairach J, Tournoux P: Co-planar Stereotaxic Atlas of the Human Brain. New York, Thieme Medical Publishers, 1988.

27 Gevensleben H, Holl B, Albrecht B, Schlamp D, Kratz O, Studer P, Wangler S, Rothenberger A, Moll GH, Heinrich H: Distinct EEG effects related to neurofeedback training in children with ADHD: A randomized controlled trial. Int J Psychophysiol 2009;74(2):149-57.

28 Lansbergen MM, van Dongen-Boomsma M, Buitelaar JK, Slaats-Willemse D: ADHD and EEG-neurofeedback: a double-blind randomized placebo-controlled feasibility study. J Neural Transm 2011;118(2):275-284.

29 Koprivova J, Horacek J, Tintera J, Prasko J, Raszka M, Ibrahim I, Höschl C: Medial frontal and dorsal cortical morphometric abnormalities are related to obsessive-compulsive disorder. Neurosci Lett 2009;464(1):62-66.

30 Fontenelle LF, Mendlowicz MV, Ribeiro P, Piedade RA, Versiani M: Low-resolution electromagnetic tomography and treatment response in obsessive-compulsive disorder. Int J Neuropsychopharmacol 2006;9(1):89-94.

31 Knyazev GG: Motivation, emotion, and their inhibitory control mirrored in brain oscillations. Neurosci Biobehav Rev 2007;31(3):377-95.

32 Laufs H, Kleinschmidt A, Beyerle A, Eger E, Salek-Haddadi A, Preibisch C, Krakow K: EEG-correlated fMRI of human alpha activity. Neuroimage 2003;19(4):1463-76.

33 Rauch SL, Dougherty DD, Cosgrove GR, Cassem EH, Alpert NM, Price BH, Nierenberg AA, Mayberg HS, Baer L, Jenike MA, Fischman AJ: Cerebral metabolic correlates as potential predictors of response to anterior cingulotomy for obsessive compulsive disorder. Biol Psychiatry 2001;50(9):659-67.

34 Rauch SL, Shin LM, Dougherty DD, Alpert NM, Fischman AJ, Jenike MA: Predictors of fluvoxamine response in contamination-related obsessive compulsive disorder: a PET symptom provocation study. Neuropsychopharmacology 2002;27(5):782-91.

35 Sherlin L, Congedo M: Obsessive-compulsive dimension localized using low-resolution brain electromagnetic tomography (LORETA). Neurosci Lett 2005;387:72-74.

36 Velikova S, Locatelli M, Insacco C, Semeraldi E, Comi G, Leocani L: Dysfunctional brain circuitry in obsessive-compulsive disorder: source and coherence analysis of EEG rhythms. Neuroimage 2010;49:977-983. 
37 Vogt BA, Berger GR, Derbyshire SW: Structural and functional dichotomy of human midcingulate cortex. Eur J Neurosci 2003;18(11):3134-3144.

38 Ullsperger M, von Cramon DY: Subprocesses of performance monitoring: a dissociation of error processing and response competition revealed by event-related fMRI and ERPs. Neuroimage 2001;14(6):1387-1401.

39 Pascual-Marqui RD, Lehmann D, Koenig T, Kochi K, Merlo MC, Hell D, Koukkou M: Low resolution brain electromagnetic tomography (LORETA) functional imaging in acute, neuroleptic-naive, first-episode, productive schizophrenia. Psychiatry Res 1999;90(3):169-179.

40 Choi JS, Kim HS, Yoo SY, Ha TH, Chang JH, Kim YY, Shin YW, Kwon JS. Morphometric alterations of anterior superior temporal cortex in obsessive-compulsive disorder. Depress Anxiety 2006;23(5):290-296.

41 Shin YW, Yoo SY, Lee JK, Ha TH, Lee KJ, Lee JM, Kim IY, Kim SI, Kwon JS. Cortical thinning in obsessive compulsive disorder. Hum Brain Mapp. 2007;28(11):1128-1135.

42 Maihöfner C, Sperling W, Kaltenhäuser M, Bleich S, de Zwaan M, Wiltfang J, Thürauf N, Elstner S, Reulbach U, Lewczuk P, Kornhuber J, Ropohl A. Spontaneous magnetoencephalographic activity in patients with obsessive-compulsive disorder. Brain Res. 2007 ;1129(1):200205.

43 Nagai M, Kishi K, Kato S: Insular cortex and neuropsychiatric disorders: a review of recent literature. Eur Psychiatry 2007;22(6):387-394.

44 Shapira NA, Liu Y, He AG, Bradley MM, Lessig MC, James GA, Stein DJ, Lang PJ, Goodman WK: Brain activation by disgust-inducing pictures in obsessive-compulsive disorder. Biol Psychiatry 2003;54(7):751-756.

45 Ciesielski KT, Rauch SL, Ahlfors SP, Vangel ME, Wilhelm S, Rosen BR, Hämäläinen MS: Role of medial cortical networks for anticipatory processing in obsessive-compulsive disorder. Hum Brain Mapp 2011; doi: 10.1002/hbm.21341. 


\section{TABLES:}

Table 1: Abnormal component frequencies that were chosen for the training and downtrained in the NFB group.

\begin{tabular}{|lcc|}
\hline & Neurofeedback & Sham feedback \\
Patient 1 & $5-6 \mathrm{~Hz}$ & $5-7 \mathrm{~Hz}$ \\
Patient 2 & $6-8 \mathrm{~Hz}$ & $3-7 \mathrm{~Hz}$ \\
Patient 3 & $4-8 \mathrm{~Hz}$ & $6-8 \mathrm{~Hz}$ \\
Patient 4 & $13-15 \mathrm{~Hz}$ & $7-8 \mathrm{~Hz}$ \\
Patient 5 & $5-6 \mathrm{~Hz}$ & $6-8 \mathrm{~Hz}$ \\
Patient 6 & $5-8 \mathrm{~Hz}$ & $4-6 \mathrm{~Hz}$ \\
Patient 7 & $13-16 \mathrm{~Hz}$ & $14-15 \mathrm{~Hz}$ \\
Patient 8 & $5 \mathrm{~Hz}$ & $3-7 \mathrm{~Hz}$ \\
Patient 9 & $4-7 \mathrm{~Hz}$ (dropped out) & $6-7 \mathrm{~Hz}$ \\
Patient 10 & $4-6 \mathrm{~Hz}$ (dropped out) & $6-9 \mathrm{~Hz}$ \\
\hline
\end{tabular}

Table 2: Demographic and clinical characteristics of the groups of subjects.

\begin{tabular}{|c|c|c|c|c|c|c|c|c|}
\hline & $\begin{array}{l}\text { All patients } \\
\text { (pre-tr.) } \\
(\mathrm{N}=18)\end{array}$ & $\begin{array}{l}\text { NFB } 1 \text { (pre- } \\
\text { treatment) } \\
\quad(\mathrm{N}=8)\end{array}$ & $\begin{array}{l}\text { SFB } 1 \text { (pre- } \\
\text { treatment) } \\
(N=10)\end{array}$ & $\begin{array}{l}\text { All } \\
\text { patients } \\
\text { (post-tr.) } \\
(\mathrm{N}=18)\end{array}$ & $\begin{array}{l}\text { NFB } 1 \\
\text { vs. } \\
\text { SFB } 1\end{array}$ & $\begin{array}{l}\text { NFB } 2 \\
\text { vs. } \\
\text { SFB } 2 \\
\text { signi }\end{array}$ & $\begin{array}{l}\text { NFB } 1 \\
\text { vs. } \\
\text { NFB } 2 \\
\text { icance }\end{array}$ & $\begin{array}{l}\text { SFB } 1 \\
\text { vs. } \\
\text { SFB } 2\end{array}$ \\
\hline Sample characteristics & number & number & number & number & $p$ & $p$ & $p$ & $p$ \\
\hline \multicolumn{9}{|l|}{ Demographic } \\
\hline sex (men:women) & $4: 14$ & $1: 7$ & $3: 7$ & $4: 14$ & 0.375 & 0.375 & NA & NA \\
\hline \multicolumn{9}{|l|}{ Education } \\
\hline & $\begin{array}{l}\text { Median } \\
\text { (range) }\end{array}$ & $\begin{array}{l}\text { Median } \\
\text { (range) }\end{array}$ & $\begin{array}{l}\text { Median } \\
\text { (range) }\end{array}$ & $\begin{array}{l}\text { Median } \\
\text { (range) }\end{array}$ & & & & \\
\hline age (years) & $26.5(19-42)$ & $24.5(19-42)$ & $28(20-38)$ & NA & 0.396 & NA & NA & NA \\
\hline \multicolumn{9}{|l|}{ Clinical symptoms } \\
\hline Y-BOCS & $24(5-33)$ & $25.5(5-33)$ & $21.5(16-28)$ & $12(2-33)$ & 0.324 & 0.788 & 0.018 & 0.028 \\
\hline Obsession subscore & $12(3-17)$ & $12.5(3-17)$ & $10.5(8-14)$ & $6.5(2-18)$ & 0.417 & 0.893 & 0.036 & 0.021 \\
\hline Compulsion subscore & $12(2-16)$ & $12.5(2-16)$ & $11(7-14)$ & $6(0-15)$ & 0.367 & 0.440 & 0.012 & 0.041 \\
\hline BAI & $20(4-42)$ & $18(6-29)$ & $29.5(4-42)$ & $10.5(2-44)$ & 0.142 & 0.350 & 0.262 & 0.044 \\
\hline BDI & $19(0-39)$ & $16.5(0-39)$ & $23.5(0-39)$ & $8.5(0-36)$ & 0.449 & 0.721 & 0.128 & 0.021 \\
\hline $\begin{array}{l}\text { Treatment response } \\
\text { (\% change of the score) }\end{array}$ & All patients & NFB & SFB & & & & & $\begin{array}{l}\text { NFB vs. } \\
\text { SFB }\end{array}$ \\
\hline Y-BOCS & $32(-4-75)$ & $52(0-62)$ & $27(-4-75)$ & NA & NA & NA & NA & 0.089 \\
\hline Obsession subscore & $27(-11-63)$ & $24(-6-62)$ & $27(-11-63)$ & NA & NA & NA & NA & 0.863 \\
\hline Compulsion subscore & $29(-13-100)$ & $56(6-100)$ & $21(-13-88)$ & NA & NA & NA & NA & 0.015 \\
\hline BAI & $33(-86-94)$ & $27(-86-53)$ & $48(-34-94)$ & NA & NA & NA & NA & 0.058 \\
\hline BDI & $14(-100-100)$ & $9(-100-68)$ & $27(-100-100)$ & NA & NA & NA & NA & 0.539 \\
\hline \multicolumn{9}{|c|}{$\begin{array}{l}\text { Abbreviations: NFB - neurofeedback, SFB - sham feedback, NFB } 1 \text { (NFB 2) - neurofeedback group before (after) treatment, } \\
\text { SFB } 1 \text { (SFB 2) - sham feedback group before (after) treatment, Y-BOCS - Yale-Brown Obsessive-Compulsive scale, BAI - Beck } \\
\text { Anxiety Inventory, BDI - Beck Depression Inventory, NA - not applied/not applicable } \\
\text { The Mann-Whitney U-test was used to compare NFB and SFB group, the Wilcoxon signed-rank test was applied to explore } \\
\text { post-treatment changes and the chi-square test was used for categorial variables. }\end{array}$} \\
\hline
\end{tabular}


Table 3: Summary of the pre- vs. post-treatment EEG comparisons.

PRE-TREATMENT EEG CORRELATIONS WITH TREATMENT RESPONSE

\begin{tabular}{|c|c|c|c|c|c|c|}
\hline & & & frequency band & $\begin{array}{l}\text { brain } \\
\text { region }\end{array}$ & $\begin{array}{l}\text { sign. stat. values in one-band } \\
\text { testing }\end{array}$ & $\begin{array}{l}\text { stat. thresholds (all bands } \\
\text { tested at once) }\end{array}$ \\
\hline \multirow{12}{*}{ sLORETA } & all & abs. power & n.s. & n.s. & n.s. & $\mathrm{t} \geq|3.46|, \mathrm{p}<0.200$, d.f. $=17$ \\
\hline & & rel. power & n.s. & n.s. & n.s. & $\mathrm{t} \geq|2.96|, \mathrm{p}<0.450$, d.f. $=17$ \\
\hline & NFB & abs. power & n.s. & n.s. & n.s. & $\mathrm{t} \geq|5.16|, \mathrm{p}<0.200$, d.f. $=7$ \\
\hline & & rel. power & n.s. & n.s. & n.s. & $\mathrm{t} \geq|3.43|, \mathrm{p}<0.700$, d.f. $=7$ \\
\hline & SFB & abs. power & n.s. & n.s. & n.s. & $\mathrm{t} \geq|2.86|, \mathrm{p}<0.600$, d.f. $=9$ \\
\hline & & rel. power & n.s. & n.s. & n.s. & $\mathrm{t} \geq|3.53|, \mathrm{p}<0.350$, d.f. $=9$ \\
\hline & all low $_{\text {low }}$ & abs. power & n.s. & n.s. & n.s. & $\mathrm{t} \geq|2.65|, \mathrm{p}<0.800$, d.f. $=14$ \\
\hline & & rel. power & n.s. & n.s. & n.s. & $\mathrm{t} \geq|2.61|, \mathrm{p}<0.650$, d.f. $=14$ \\
\hline & $\mathrm{NFB}_{\text {low }}$ & abs. power & n.s. & n.s. & n.s. & $\mathrm{t} \geq|7.76|, \mathrm{p}<0.250$, d.f. $=5$ \\
\hline & & rel. power & $\downarrow$ alpha1 $(8.5-10 \mathrm{~Hz})$ & $\begin{array}{l}\mathrm{PCC}(\mathrm{BA} \\
31)\end{array}$ & $\mathrm{t} \leq-8.24, \mathrm{p}<0.050$, d.f. $=5$ & $\mathrm{t} \geq|9.48|, \mathrm{p}<0.058$, d.f. $=5$ \\
\hline & $\mathrm{SFB}_{\text {low }}$ & abs. power & n.s. & n.s. & n.s. & $\mathrm{t} \geq|3.06|, \mathrm{p}<0.500$, d.f. $=8$ \\
\hline & & rel. power & n.s. & n.s. & n.s. & $\mathrm{t} \geq|3.26|, \mathrm{p}<0.450$, d.f. $=8$ \\
\hline \multirow{16}{*}{$\operatorname{Tr} C$} & all & abs. power & n.s. & n.s. & NA & $\mathrm{t} \geq|2.32|, \mathrm{p}<0.250$, d.f. $=17$ \\
\hline & & rel. power & n.s. & n.s. & NA & $\mathrm{t} \geq|2.48|, \mathrm{p}<0.150$, d.f. $=17$ \\
\hline & NFB & abs. power & $\downarrow$ beta3 $(25-26 \mathrm{~Hz})$ & $\operatorname{TrC}$ & NA & $\mathrm{t} \geq|4.12|, \mathrm{p}<0.030$, d.f. $=7$ \\
\hline & & rel.power & n.s. & n.s. & NA & $\mathrm{t} \geq|1.69|, \mathrm{p}<0.550$, d.f. $=7$ \\
\hline & SFB & abs. power & n.s. & n.s. & NA & $\mathrm{t} \geq|1.22|, \mathrm{p}<0.900$, d.f. $=9$ \\
\hline & & rel.power & n.s. & n.s. & NA & $\mathrm{t} \geq|2.07|, \mathrm{p}<0.400$, d.f. $=9$ \\
\hline & $\mathrm{all}_{\text {low }}$ & abs. power & n.s. & n.s. & NA & $\mathrm{t} \geq|1.86|, \mathrm{p}<0.550$, d.f. $=14$ \\
\hline & & rel.power & n.s. & n.s. & NA & $\mathrm{t} \geq|2.36|, \mathrm{p}<0.200$, d.f. $=14$ \\
\hline & $\mathrm{NFB}_{\text {low }}$ & abs. power & n.s. & n.s. & NA & $\mathrm{t} \geq|2.82|, \mathrm{p}<0.200$, d.f. $=5$ \\
\hline & & rel.power & n.s. & n.s. & NA & $\mathrm{t} \geq|1.89|, \mathrm{p}<0.450$, d.f. $=5$ \\
\hline & $\mathrm{SFB}_{\text {low }}$ & abs. power & n.s. & n.s. & NA & $\mathrm{t} \geq|0.78|, \mathrm{p}<0.950$, d.f. $=8$ \\
\hline & & rel. power & n.s. & n.s. & NA & $\mathrm{t} \geq|1.82|, \mathrm{p}<0.550$, d.f. $=8$ \\
\hline & NFB-SFB*pre-post & abs. power & n.s. (IDF) & n.s. $(\operatorname{TrC})$ & n.s. $(F=1.05, p \leq 0.322$, d.f. $=16)$ & NA \\
\hline & & rel.power & n.s. (IDF) & n.s. $(\operatorname{TrC})$ & n.s. $(F=1.00, p \leq 0.331$, d.f. $=16)$ & NA \\
\hline & $\begin{array}{l}\mathrm{NFB}_{\text {low }}-\mathrm{SFB}_{\text {low }} * \text { pre- } \\
\text { post }\end{array}$ & abs. power & n.s. (IDF) & n.s. $(\operatorname{TrC})$ & n.s. $(F=0.86, p \leq 0.369$, d.f. $=13)$ & NA \\
\hline & & rel.power & n.s. (IDF) & n.s. $(\operatorname{TrC})$ & n.s. $(F=1.73, p \leq 0.212$, d.f. $=13)$ & NA \\
\hline
\end{tabular}

Abbreviations and symbols: sLORETA - standardized low-resolution electromagnetic tomography, TrC - EEG component selected for the training (anterior cingulate, insula, middle and superior fontal gyrus, paracentral lobule, parahippocampal and subcallosal gyrus), NFB - neurofeedback group, SFB - sham feedback group, all - all patients (NFB and SFB group), $\mathrm{NFB}_{\text {low }}$ - neurofeedback low-frequency subgroup, $\mathrm{SFB}_{\text {low }}$-sham feedback low-frequency subgroup, all low $_{\text {lom }}$ - low-frequency subgroup of all patients $\left(\mathrm{NFB}_{\text {low }}\right.$ and $\left.\mathrm{SFB}_{\text {low }}\right)$, n.s. - not significant, $\downarrow$ - post-treatment decrease, PCC - posterior cingulate cortex, NA - not applied/not applicable. 
Table 4: Summary of the pre-treatment EEG correlations with treatment response.

\section{PRE-TREATMENT EEG CORRELATIONS WITH TREATMENT RESPONSE}

\begin{tabular}{|c|c|c|c|c|c|}
\hline & & frequency band & brain region & $\begin{array}{l}\text { sign. stat. values in one-band } \\
\text { testing }\end{array}$ & $\begin{array}{l}\text { stat. thresholds (all bands tested } \\
\text { at once) }\end{array}$ \\
\hline \multicolumn{6}{|c|}{ Pre-tr. EEG and Y-BOCS score post-treatment } \\
\hline \multirow[t]{8}{*}{ sLORETA all } & abs. power & n.s. & n.s. & n.s. & $\mathrm{r} \geq|0.55|, \mathrm{p}<0.300$, d.f. $=16$ \\
\hline & rel.power & n.s. & n.s. & n.s. & $\mathrm{r} \geq|0.58|, \mathrm{p}<0.450$, d.f. $=16$ \\
\hline & abs. power & delta $+(1-6 \mathrm{~Hz})$ & MFC and R parahipp. gyrus & $r \geq 0.66, p<0.050$, d.f. $=13$ & $\mathrm{r} \geq|0.77|, \mathrm{p}<0.050$, d.f. $=13$ \\
\hline & & alpha1 + $(8.5-10 \mathrm{~Hz})$ & $\begin{array}{l}\text { L inf., mid., sup. TG, L insula, bilat. } \\
\text { parahippocampal gyrus and uncus }\end{array}$ & $\mathrm{r} \geq 0.77, \mathrm{p}<0.010$, d.f. $=13$ & \\
\hline & & alpha $1+(8.5-10 \mathrm{~Hz})$ & $\begin{array}{l}\text { L fusiform and parahipp. gyrus (BA } \\
\text { 20, BA 36), inf. TG }\end{array}$ & $\mathrm{r} \geq 0.79, \mathrm{p}<0.005$, d.f. $=13$ & \\
\hline & & beta $2+(18.5-21 \mathrm{~Hz})$ & OFC, MFC, DLPFC & $\mathrm{r} \geq 0.70, \mathrm{p}<0.050$, d.f. $=13$ & \\
\hline & rel.power & alpha $1+(8.5-10 \mathrm{~Hz})$ & $\begin{array}{l}\text { L inf., mid., sup., transverse TG, } \\
\text { insula, precentral and postcentral g., } \\
\text { inf. parietal lobule }\end{array}$ & $\mathrm{r} \geq 0.80, \mathrm{p}<0.010$, d.f. $=13$ & $\mathrm{r} \geq|0.87|, \mathrm{p}<0.010$, d.f. $=13$ \\
\hline & & alpha $1+(8.5-10 \mathrm{~Hz})$ & $\begin{array}{l}\text { L mid., sup. and transv. TG, } \\
\text { postcentral gyrus, inf. parietal lobule }\end{array}$ & $\mathrm{r} \geq 0.81, \mathrm{p}<0.005$, d.f. $=13$ & \\
\hline \multirow[t]{5}{*}{$\operatorname{TrC}$} & abs. power & n.s. & n.s. & NA & $\mathrm{r} \geq|0.43|, \mathrm{p}<0.350$, d.f. $=16$ \\
\hline & rel.power & n.s. & n.s. & NA & $\mathrm{r} \geq|0.38|, \mathrm{p}<0.600$, d.f. $=16$ \\
\hline & & & & & \\
\hline & abs. power & n.s. & n.s. & NA & $\mathrm{r} \geq|0.66|, \mathrm{p}<0.070$, d.f. $=13$ \\
\hline & rel.power & n.s. & n.s. & NA & $\mathrm{r} \geq|0.66|, \mathrm{p}<0.075$, d.f. $=13$ \\
\hline
\end{tabular}

\section{Pre-tr. EEG and \% change of Y-BOCS score}

\begin{tabular}{|c|c|c|c|c|c|c|}
\hline \multirow[t]{9}{*}{ sLORETA } & all & abs. power & n.s. & n.s. & n.s. & $\mathrm{r} \geq|0.48|, \mathrm{p}<0.500$, d.f. $=16$ \\
\hline & \multirow{8}{*}{$\mathrm{all}_{\text {low }}$} & \multirow[t]{2}{*}{ rel.power } & alpha1 - $(8.5-10 \mathrm{~Hz})$ & $\begin{array}{l}\text { L mid. and superior TG, postcentral } \\
\text { gyrus and insula }\end{array}$ & $\mathrm{r} \leq-0.64, \mathrm{p}<0.050$, d.f. $=16$ & \multirow[t]{2}{*}{$\mathrm{r} \geq|0.69|, \mathrm{p}<0.100$, d.f. $=16$} \\
\hline & & & beta3 + (21.5 - $32 \mathrm{~Hz})$ & $\begin{array}{l}\text { med., mid. and sup. FG (BA 6), } \\
\text { cingulate g. (BA 24, 31), pre- and } \\
\text { postcentral gyrus, paracentral lob., } \\
\text { precuneus, R insula, inf. parietal } \\
\text { lobule, sup. and mid. TG }\end{array}$ & $r \geq 0.65, p<0.050$, d.f. $=16$ & \\
\hline & & \multirow[t]{2}{*}{ abs. power } & alpha1 - $(8.5-10 \mathrm{~Hz})$ & $\begin{array}{l}\text { L fusiform and parahippocampal } \\
\text { gyrus, uncus }\end{array}$ & $\mathrm{r} \leq-0.74, \mathrm{p}<0.010$, d.f. $=13$ & \multirow[t]{2}{*}{$\mathrm{r} \geq|0.75|, \mathrm{p}<0.030$, d.f. $=13$} \\
\hline & & & alpha1 - $(8.5-10 \mathrm{~Hz})$ & L fusiform and parahipp. gyrus & $\mathrm{r} \leq-0.76, \mathrm{p}<0.005$, d.f. $=13$ & \\
\hline & & \multirow[t]{4}{*}{ rel.power } & alpha1 - $(8.5-10 \mathrm{~Hz})$ & $\begin{array}{l}\text { widespread L temporo-parieto- } \\
\text { occipital region }\end{array}$ & $\mathrm{r} \leq-0.77, \mathrm{p}<0.010$, d.f. $=13$ & \multirow[t]{4}{*}{$r \geq|0.84|, p<0.015$, d.f. $=13$} \\
\hline & & & alpha1 - $(8.5-10 \mathrm{~Hz})$ & $\begin{array}{l}\text { L sup., mid., inf. TG, postcentral and } \\
\text { precentral gyrus, insula, fusiform } \\
\text { gyrus }\end{array}$ & $\mathrm{r} \leq-0.80, \mathrm{p}<0.005$, d.f. $=13$ & \\
\hline & & & beta3 + $(21.5-32 \mathrm{~Hz})$ & $\begin{array}{l}\text { cingulate g. (BA 23, 24, 25, 31, 33), } \\
\text { med., mid. and sup. FG (BA 6), } \\
\text { precuneus and sup. and inf. parietal } \\
\text { lob., paracentral lob., postcentral g., } \\
\text { insula, R parahipp., sup. temporal and } \\
\text { fusiform gyrus }\end{array}$ & $r \geq 0.71, p<0.050$, d.f. $=13$ & \\
\hline & & & beta3 + $(21.5-32 \mathrm{~Hz})$ & $\begin{array}{l}\text { cingulate gyrus (BA 23, 31), } \\
\text { paracentral lobule (BA 4, 5, 31) and } \\
\text { med. FG (BA 6) }\end{array}$ & $\mathrm{r} \geq 0.77, \mathrm{p}<0.015$, d.f. $=13$ & \\
\hline \multirow[t]{5}{*}{$\operatorname{TrC}$} & \multirow[t]{2}{*}{ all } & abs. power & n.s. & n.s. & NA & $\mathrm{r} \geq|0.32|, \mathrm{p}<0.700$, d.f. $=16$ \\
\hline & & rel.power & beta3 $+(25-30 \mathrm{~Hz})$ & $\operatorname{TrC}$ & NA & $\mathrm{r} \geq|0.63|, \mathrm{p}<0.050$, d.f. $=16$ \\
\hline & \multirow[t]{3}{*}{$\mathrm{all}_{\text {low }}$} & abs. power & n.s. & n.s. & NA & $\mathrm{r} \geq|0.45|, \mathrm{p}<0.400$, d.f. $=13$ \\
\hline & & rel.power & $\begin{array}{l}\text { beta3 }+ \text { at }(23-30 \\
\mathrm{Hz})\end{array}$ & $\operatorname{TrC}$ & NA & $\mathrm{r} \geq|0.67|, \mathrm{p}<0.050$, d.f. $=13$ \\
\hline & & & beta $3+(25-28 \mathrm{~Hz})$ & $\operatorname{TrC}$ & & $\mathrm{r} \geq|0.74|, \mathrm{p}<0.015$, d.f. $=13$ \\
\hline
\end{tabular}

Abbreviations and symbols: sLORETA - standardized low-resolution electromagnetic tomography, TrC - EEG component selected for the training (anterior cingulate, insula, middle and superior fontal gyrus, paracentral lobule, parahippocampal and subcallosal gyrus), NFB - neurofeedback group, SFB - sham feedback group, all - all

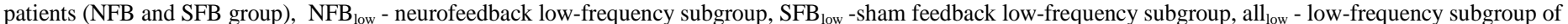
all patients $\left(\mathrm{NFB}_{\text {low }}\right.$ and $\left.\mathrm{SFB}_{\text {low }}\right)$, Y-BOCS - Yale-Brown Obsessive-Compulsive Rating Scale, n.s. - not significant, -/+ - negative/positive correlation, L - left, R right, MFC - medial frontal cortex, TG - temporal gyrus, ACC - anterior cingulate cortex, OFC - orbitofrontal cortex, DLPFC - dorsolateral prefrontal cortex, FG frontal gyrus, NA - not applied. 


\section{FIGURES:}

Fig. 1: Study design.

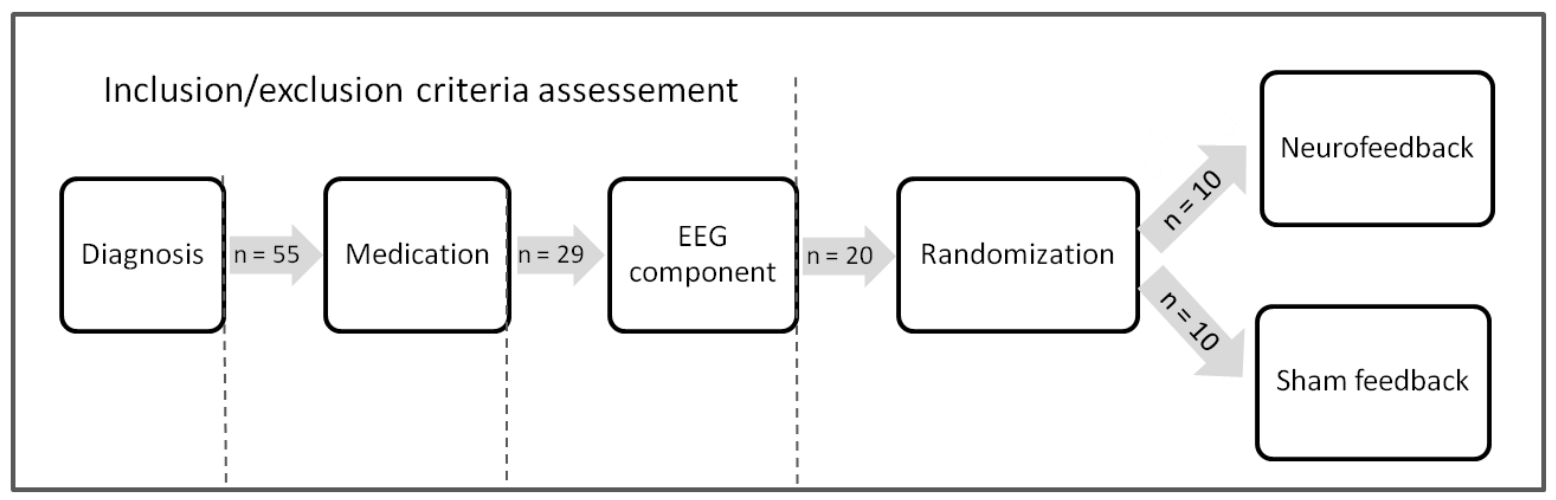

Fig. 2: An example of a normative ICA comparison in one patient. The plot shows absolute and relative power of the independent EEG component selected for the training. The patient had elevated relative power between 4 and $6 \mathrm{~Hz}$ as indicated by the disks exceeding the upper limit of the $95 \%$ confidence interval (dotted line). Therefore, in this case the frequency between $4-6 \mathrm{~Hz}$ was chosen for the training.

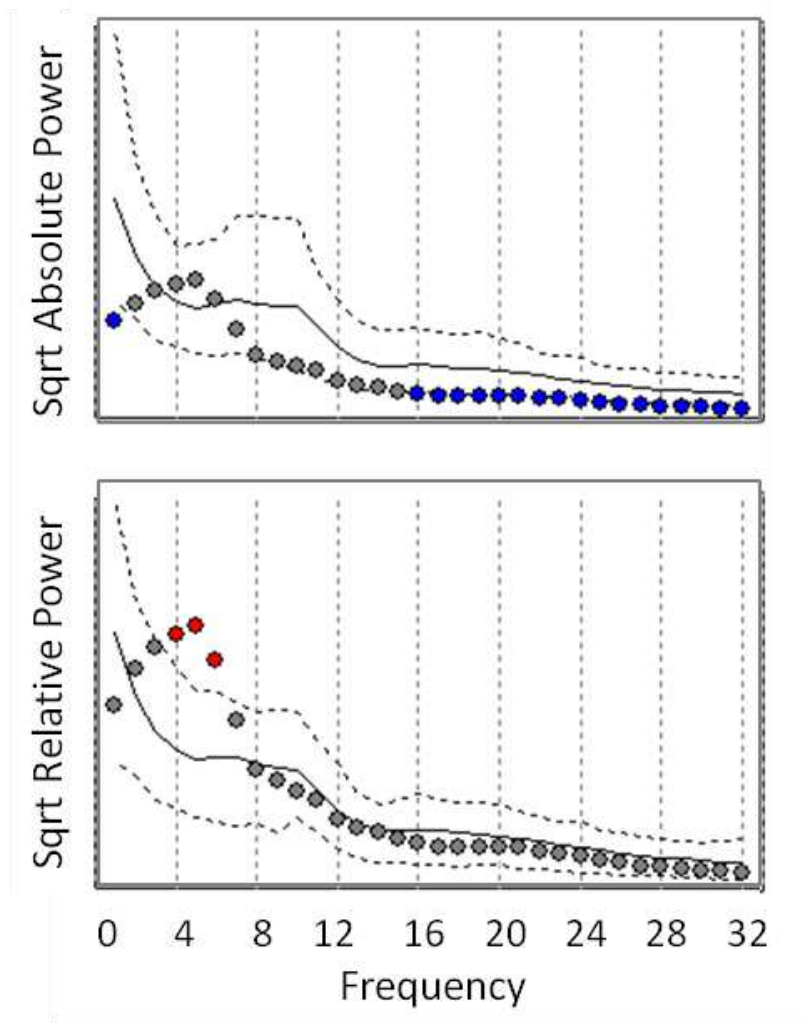


Fig. 3: Absolute and relative power of the selected component before and after neurofeedback and sham feedback. The disks above the upper dotted line signify values exceeding the 95. percentile of the normative database.

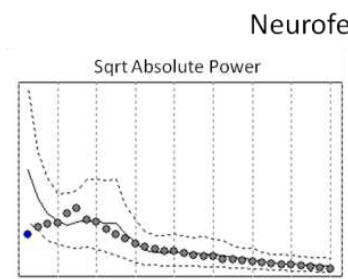

Sqrt Relative Power

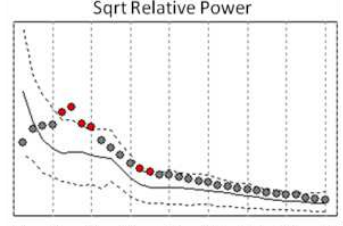

$\begin{array}{llllllllllllllllll}0 & 4 & 8 & 12 & 16 & 20 & 24 & 28 & 32 & 0 & 4 & 8 & 12 & 16 & 20 & 24 & 28 & 32\end{array}$ pre-treatment

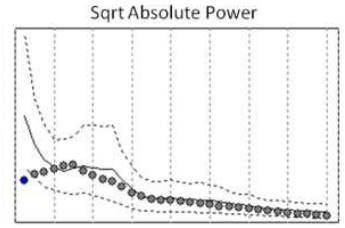

Sqrt Relative Power

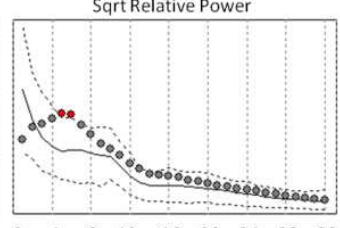

post-treatment
Sham feedback

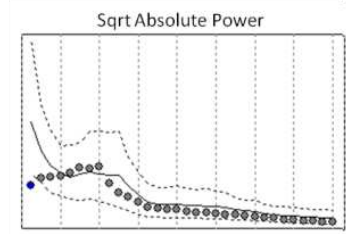

Sqrt Relative Power
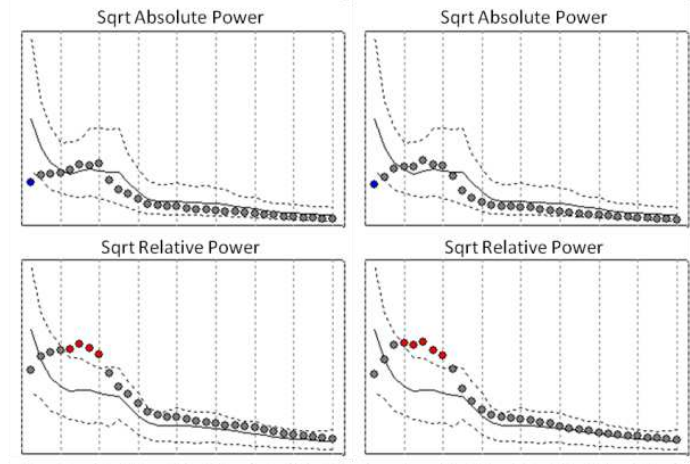

Sqrt Relative Power

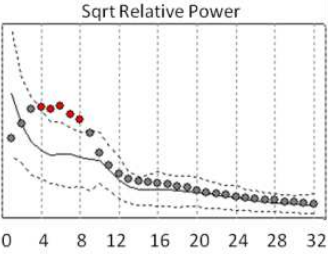

pre-treatment

Fig. 4: ANOVA results for the averaged relative power of the component 1 (Congedo et al., 2010) in individually defined frequency bands selected for the training $(F=1.00, p \leq 0.331)$.

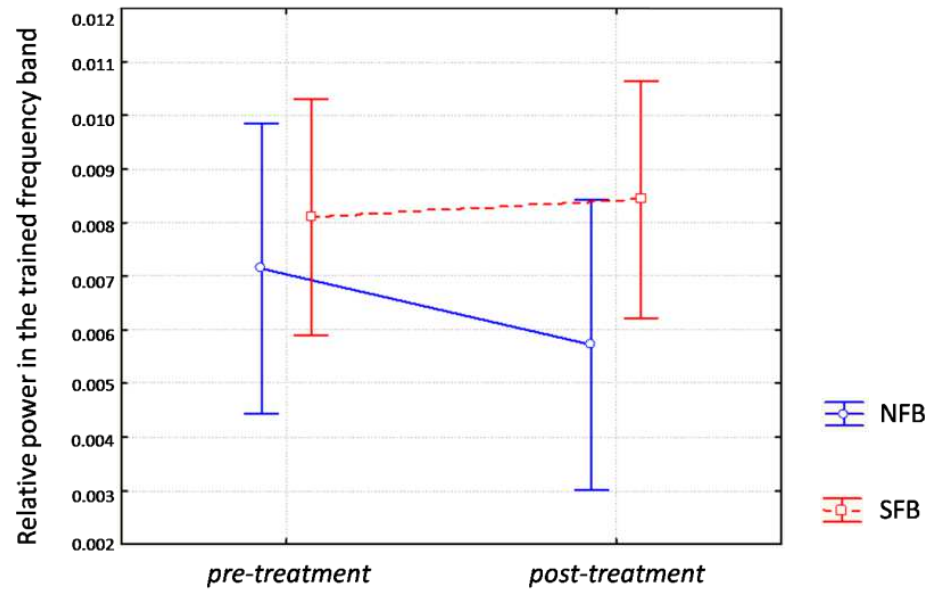

Fig. 5: Pre-treatment absolute delta power correlation trend with Y-BOCS score post-treatment $(r \geq 0.660, p<0.05)$ in subjects ( $n=15)$ with pre-treatment low-frequency excess in the component 1 by Congedo et al. (2010). Voxels correlating at $r \geq 0.660$ are coloured - a darker colour signifies stronger correlation. The result is corrected for multiple comparisons. The image is sliced at its own maximum.

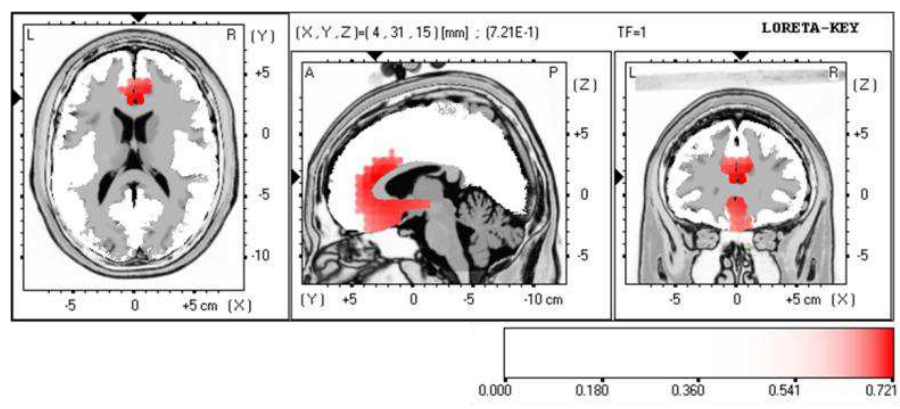


Fig. 6: Pre-treatment absolute beta2 $(18.5-21 \mathrm{~Hz})$ power correlation with the with the Yale-Brown Obsessive-Compulsive Rating Scale (Y-BOCS) score post-treatment $(r \geq 0.695, p<0.05)$ in subjects $(n=15)$ with pre-treatment low-frequency excess in the component 1 by Congedo et al. (2010). Voxels correlating at $r \geq 0.695$ are in red - a darker colour signifies stronger correlation. The result is corrected for multiple comparisons. The image is sliced at its own maximum.

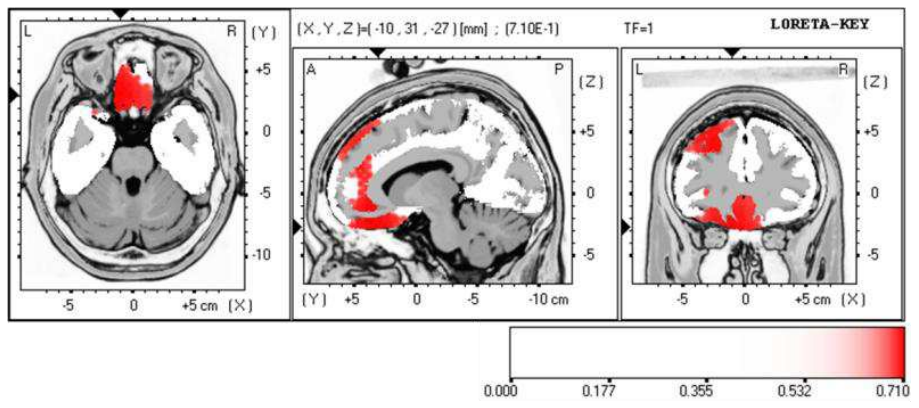

Fig. 7: Pre-treatment relative alpha1 $(8.5-10 \mathrm{~Hz})$ power correlations with percentage change of the Yale-Brown ObsessiveCompulsive Rating Scale (Y-BOCS) score post-treatment $(r \leq-0.635, p<0.05)$ in the whole group $(n=18)$. Significant voxels are in blue - darker colour signifies stronger correlation. The results are corrected for multiple comparisons. The image is sliced at its own maximum.

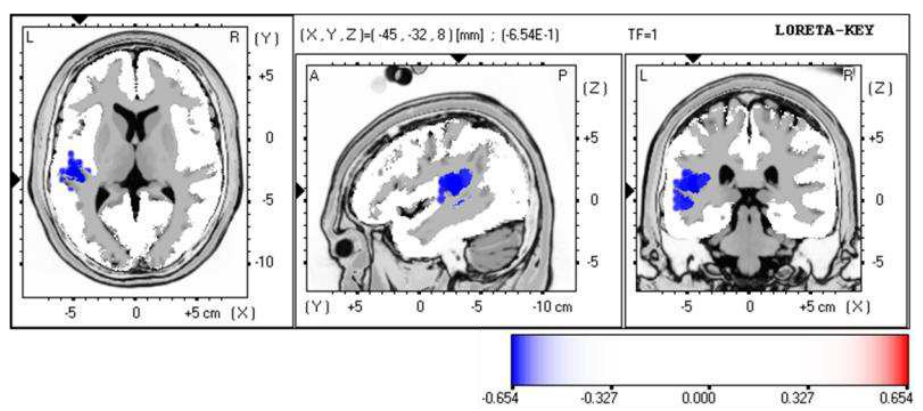

Fig. 8: Pre-treatment relative beta3 $(21.5-32 \mathrm{~Hz})$ power correlations with percentage change of the Yale-Brown ObsessiveCompulsive Rating Scale (Y-BOCS) score post-treatment $(r \geq 0.653, p<0.05)$ in the whole group $(n=18)$. Significant voxels are in red - a darker colour signifies stronger correlation. The results are corrected for multiple comparisons. The image is sliced at its own maximum.

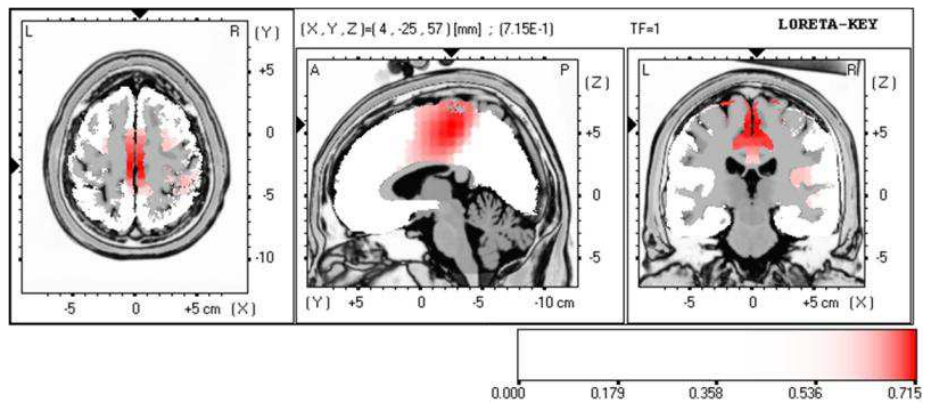

